\title{
Information-Seeking Behavior in the Digital Age: A Multidisciplinary Study of Academic Researchers
}

\section{Xuemei Ge}

\begin{abstract}
This article focuses on how electronic information resources influence the information-seeking process in the social sciences and humanities. It examines the information-seeking behavior of scholars in these fields, and extends the David Ellis model of information-seeking behavior for social scientists, which includes six characteristics: starting, chaining, browsing, differentiating, monitoring, and extracting. The study was conducted at Tennessee State University (TSU). Thirty active social sciences and humanities faculty, as well as doctoral students, were interviewed about their use of electronic information resources for research purposes, their perception of electronic and print materials, their opinions concerning the Ellis model, and ways the model might apply to them. Based on the interview results, the researcher provides suggestions on how current information services and products can be improved to better serve social sciences and humanities researchers. The author makes recommendations for improving library services and technologies to better meet the needs of social sciences and humanities scholars.
\end{abstract}

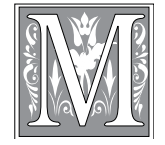

odern modes of technology have changed the information environment in which social sciences and humanities researchers work. The pursuit of knowledge has been revolutionized, mainly through the vast expansion of data accessible via the Internet. Increased knowledge of the information-seeking behaviors of social sciences and humanities researchers is crucial to meeting their information needs.

The electronic information resources examined in this study include:

1. Electronic mail

2. Listservs

3. Web sites
4. FTP (file transfer protocol)

5. Online catalogs

6. Electronic journals

7. Databases

8. Web portals

David Ellis proposed a behavior model of information-seeking behavior based on observations of social scientists. The model includes six fundamental characteristics of information seeking: starting, chaining, browsing, differentiating, monitoring, and extracting. ${ }^{1}$

This study seeks to understand how electronic information resources affect the information-seeking processes in the social sciences and humanities. It also

Xuemei Ge is Metadata Librarian in Brown-Daniel Library at Tennessee State University; e-mail: xge@ tnstate.edu. (C) Xuemei Ge 
endeavors to discover how technology contributes to and perhaps alters the information-seeking process and explores the applicability of Ellis's model in the digital information environment. The findings of this study provide suggestions on how current information services and systems can be improved to better serve social sciences and humanities researchers as they navigate this new data-rich environment.

The study addresses the following specific research questions:

1. What roles do electronic information resources play in social sciences and humanities researchers' information seeking behavior?

2. How do social sciences and humanities researchers use electronic information resources in their information seeking?

3. What factors affect these researchers' use of electronic information resources?

4. To what extent is Ellis's behavior model applicable to the digital information environment?

\section{Literature Review}

Research findings concerning the use of electronic resources by social scientists and humanities scholars vary, but recent studies show an increase in the use of electronic resources. A study of Brazilian social sciences researchers found that, although print resources are still the most frequently used, electronic resources are becoming increasingly popular. Access to networked computers is the main obstacle to the use of databases and other electronic resources. ${ }^{2}$ Hannah Francis focused on a study that described the informationseeking behavior of social sciences faculty at the University of the West Indies (UWI). One of this 2005 study's findings was that social scientists prefer journal articles in electronic format over print. ${ }^{3}$ David Ellis and Hanna Oldman's study explored the information-seeking behavior of researchers in the field of English literature at British universities. The article concluded with recommendations for further study of the use of electronic resources in relation to information literacy and brows- ing. ${ }^{4}$ Stephen E. Wiberley, Jr. and William G. Jones revealed that temporal factors have a significant impact on humanists' adoption of electronic information technology and identified and described four types of time intervals that influence humanists' behavior. Three are types of time spent: anticipated start-up time, actual start-up time, and use time; the fourth is time of life: that is, the stage or trajectory of a scholar's project or career. ${ }^{5}$ Margaret Stieg Dalton and Laurie Charnigo studied historians' attitudes toward and use of electronic materials and found that the application of electronic resources have increased historians' use of online catalogs and indexes in their efforts to identify appropriate primary and secondary sources of information. ${ }^{6}$ Susana Romanos de Tiratel investigated the informationseeking behavior of Argentine humanities and social sciences scholars in 2000, and found no substantial differences between them, concluding they share similar information-seeking behaviors. ${ }^{7}$ Peiling Wang wrote about disciplinary and cultural differences among information seekers in the Internet age, concluding that there are differences across disciplines and cultures in terms of how they rank the importance of these resources and how much they use them. ${ }^{8}$ In her 2007 paper about the information-seeking behaviors of academic researchers in the Internet age, a user study in the United States, China, and Greece, Wang further discussed the information needs, information-seeking behaviors, and resource use of selected special interest groups. ${ }^{9}$ In their review of scholarly information practices in the online environment, Carole L. Palmer, Lauren C. Teffeau, and Carrie M. Pirmann began to address the problem by reporting on the state of knowledge on scholarly information behavior, focusing on the information-seeking activities involved in the research process and how they differ across disciplines. The report found that information practices may be enhanced or advanced by new information resources and tools. What has changed in 
the digital environment is not the value of these kinds of sources, but rather how they are searched, accessed, and used in the scholarly process. ${ }^{10}$ Clara M. Chu studied the information needs of literary critics while producing literary criticism and developed a six-stage model of producing literary criticism, which includes ideas, preparation, elaboration, analysis and writing, dissemination, and further writing and dissemination. ${ }^{11}$

The study of electronic informationseeking behavior in the social sciences and humanities dates back to the 1980s, but David Ellis was the first to model the process of information-seeking behavior of social scientists: how they search for and interact with the materials, as opposed to the sources they use and the manner in which the materials are obtained. Ellis described six fundamental characteristics of information seeking practiced by social scientists: starting, chaining, browsing, differentiating, monitoring, and extracting. Starting refers to the information-seeking patterns of researchers beginning work in a new area. Chaining describes the process of following chains of citations or other forms of referential connection between materials or sources identified during "starting" activities. Browsing is defined as "semi-directed or semi-structured searching in an area of potential interest." Differentiating involves "identifying different sets of sources in terms of the differing probability of their containing useful material." Monitoring is an activity limited to those people following developments in specialized areas. Finally, extracting refers to "the activity of going through a particular source and selectively identifying relevant materials from that source." 12 It should also be noted that Ellis conducted another study about information-seeking patterns of academic researchers in 1993. Ellis's comparison of the different activities reported by social scientists led to the conclusion that these six categories were sufficient to represent the different information-seeking patterns of researchers. ${ }^{13}$
Most of the information-seeking behavior categories in Ellis's model are supported by capabilities available in common Web browsers. Thus, an individual could initiate surfing the Web from one of a few favorite Web sites (starting); follow hypertext links to related information resources in both backward- and forwardlinking directions (chaining); scan the Web pages of the sources selected (browsing); bookmark useful sources for future reference and visits (differentiating); subscribe to e-mail-based services that alert the user of new information or development (monitoring); and search a particular source or site for all information on that site on a particular topic (extracting). ${ }^{14,15}$

In the book, Looking for Information, Donald O. Case indicates that the Ellis model makes no claim of considering the many factors and variables generally involved in information seeking. For example, the type of need and what sort of information or "help" might satisfy it, or the availability of sources and their characteristics. ${ }^{16}$ Lokman I. Meho and Stephanie W. Haas's study on information-seeking behavior of social sciences faculty studying stateless nations revealed a frequent use of information technology, with 88 percent of participants responding that they use electronic resources. ${ }^{17}$ Access problems were a major issue for selected materials, with 83 percent of faculty reporting they travel to special collections or archives to locate historical documents. In another study, Lokman I. Mehe and Helen R. Tibbo revised Ellis's information-seeking behavior model, using a specialized case study of social sciences faculty researching stateless nations. They developed a model which differs from Ellis's, grouping all information-seeking behavior into four interrelated stages: searching, accessing, processing, and ending. ${ }^{18}$

\section{Methodology Research Design}

This study adopts a qualitative approach to information-seeking behavior, using 
the interview method as the primary tool for data collection. The presence of an interviewer improves response rates and quality of answers, since interviewers can clarify questions as well as ask follow-up questions. The interviews were recorded and transcribed.

\section{Interview Guideline}

The interview design was semi-structured and included both closed and open-ended questions. After a review of the existing literature, interview questions were developed that described information use patterns, methods of locating information, and use of information technology, with a particular emphasis on electronic resources. An Interview Guideline was designed to systematically collect data (see Appendix A). The Interview Guideline consisted of a series of thirteen questions intended to drive the interview process. Initial interview questions were developed from domains that emerged from literature review in concert with the researcher's experience. The first question asked the interviewee to briefly describe a recent research project which required library research or access to scholarly information. This question grounded the interviewer and the interviewee in a specific research situation when responding to subsequent questions about information resources used to support research. Questions 2 through 9 were structured questions about the use of eight types of electronic resources, such as the Web, e-mail, and FTP. Each question had three subsequent sections regarding usage frequency and number of years of use, as well as an importance rating. Question 10 asked the interviewees to compare their use of print resources with their use of electronic resources. Question 11, an open-ended question, gave the interviewees the opportunity to freely comment on the mentioned electronic resources and to elaborate on how and why each source was selected. Question 12, also an open-ended question, segued the interview to Ellis's behavior model. The model was presented to the interviewee, and comments were solicited. The final question offered the interviewee another opportunity to add any comments to the interview. The questions in the Interview Guideline attempted to address the researcher's questions about what roles electronic information resources play in social sciences and humanities researchers' information seeking, how social sciences and humanities researchers use electronic information resources in their information seeking, which factors affect researchers' use of electronic information resources, and to what extent Ellis's behavior model is applicable to the electronic information environment.

\section{Population and Sampling}

The study was conducted at Tennessee State University in Nashville, where the researcher works. Tennessee State University is an urban land-grant university with particularly strong programs and departments in social sciences and humanities: Education, Sociology, Business, Communications, History, Geography, Political Science, and Women's Studies, Africana Studies, Literature, Philosophy and Interdisciplinary Studies. Tennessee State University has more than 460 full-time and part-time faculty members, many of whom publish regularly. During the time of the study, the university library had fewer than 400,000 monographs, 1,700 journals and possessed more than 100 databases. Currently, the university library has approximately 350,000 monographs, 168,866 ebooks, and 1,098 print and online periodical subscriptions, but possesses rich electronic resources, including more than 170 electronic databases. For the past three years, the undergraduate enrollment has been less than 8,000 , while the graduate enrollment, which includes both master's and doctoral programs, has averaged less than 2,000.

The study included two types of interviewees: faculty members and doctoral students. The researcher contacted 46 potential participants via e-mail to inquire 
about their interest in the project. Thirty active and productive social sciences and humanities faculty and doctoral students at Tennessee State University agreed to participate.

\section{Data Collection and Analysis Procedure}

Before the interview, each participant signed an informed consent form addressing voluntary participation. The interviewer provided a short introduction to the research topic. After giving definitions of the electronic resources for the study, the researcher followed the Interview Guideline (see Appendix A). Participants were asked about their work, their research habits and methodologies, and their usage of eight different electronic information resources for research purposes. The researcher took notes on a response sheet listing the questions asked. With the permission of the participants, all interviews were recorded on tape. To preserve anonymity, both the notes and tapes were given an identifying number retained only by the researcher. Individual responses were identified by the identification numbers assigned during data analysis and all recorded data were transcribed into text using these identification numbers. The interview data were coded and tabulated to facilitate analysis and comparison using both the quantitative and the qualitative analysis methods.

\section{Limitations of the Study}

Tennessee State University is mainly teaching oriented and does not have many doctoral programs in social sciences and humanities.

\section{Findings and Discussions Interview Results}

Interviews were conducted between June and December of 2004 and took place in participants' departmental offices. The length of the interviews ranged from 45 to 90 minutes, with the majority lasting about an hour. At the end of the data collection process, all interview data, relevant portions of the taped interviews, and notes were transformed into MS Word files. Transcripts ranged from 1,400 to 3,600 words and generated enough data to provide a detailed and accurate account of researchers' perceptions of their information-seeking activities. Topics discussed included researchers' use of electronic information resources, their perceptions of electronic and print resources, the problems they encountered in the research process, their methods of keeping abreast of new developments in the field, their help-seeking behaviors, and their opinions as to whether David Ellis's information-seeking behavior model was applicable to their research. The overall goal was to assess how technology contributes to the information-seeking process for social sciences and humanities researchers and to determine how well Ellis's model applies to new technologies. The research verified the Ellis model and revealed potential new features.

\section{The Participants}

The 30 participants interviewed were diverse in terms of gender, rank, discipline, and research topics. Social sciences researchers in the study included individuals who conduct research in the

\section{TABLE 1}

Participants by Rank and Gender $(n=30)$

\begin{tabular}{|l|c|c|c|c|c|}
\hline & $\begin{array}{c}\text { Doctoral } \\
\text { Student }\end{array}$ & $\begin{array}{c}\text { Assistant } \\
\text { Professor }\end{array}$ & $\begin{array}{c}\text { Associate } \\
\text { Professor }\end{array}$ & Professor & Row Total \\
\hline Male & $4(13.3 \%)$ & $4(13.3 \%)$ & $4(13.3 \%)$ & $7(23.3 \%)$ & $19(63.2 \%)$ \\
\hline Female & $5(16.7 \%)$ & $4(13.3 \%)$ & $1(3.3 \%)$ & $1(3.3 \%)$ & $11(36.6 \%)$ \\
\hline Column Total & $9(30.0 \%)$ & $8(26.6 \%)$ & $5(16.6 \%)$ & $8(26.6 \%)$ & $30(99.8 \%)^{*}$ \\
\hline * Due to rounding
\end{tabular}




\begin{tabular}{|l|l|c|}
\hline \multicolumn{2}{|c|}{ TABLE 2 } \\
\multicolumn{2}{|c|}{ Participants by Discipline (n= 30) } \\
\hline Broad Category & Discipline & Number of Participants \\
\hline Social Sciences & Ed. Administration & $10(33.3 \%)$ \\
\cline { 2 - 3 } & Teaching \& Learning & $5(16.7 \%)$ \\
\cline { 2 - 3 } & Hotel Management & $3(10.0 \%)$ \\
\cline { 2 - 3 } & Sociology & $2(6.7 \%)$ \\
\cline { 2 - 3 } & Business Administration & $1(3.3 \%)$ \\
\cline { 2 - 3 } & Geography & $1(3.3 \%)$ \\
\cline { 2 - 3 } & Political Science & $1(3.3 \%)$ \\
\hline \multirow{5}{*}{ Humanities } & History & $2(6.7 \%)$ \\
\cline { 2 - 3 } & African Studies & $2(6.7 \%)$ \\
\cline { 2 - 3 } & Women's Studies & $1(3.3 \%)$ \\
\cline { 2 - 3 } & Literature \& Philosophy & $1(3.3 \%)$ \\
\cline { 2 - 3 } & Communication & $1(3.3 \%)$ \\
\hline
\end{tabular}

fields of Educational Administration, Teaching \& Learning, Hotel Management, Sociology, Business Administration, Geography, and Political Science. Individuals conducting research in the fields of History, Africana Studies, Women's Studies, and Literature \& Philosophy were classified as humanities researchers. A participant from the Communications department was also considered a humanities researcher, since the participant teaches Theater classes and conducts research in the humanities (see table 1 and table 2).

\section{Use of Electronic Information Resources in Research}

The data obtained from the interviewees provides insight into the role of electronic information resources in informationseeking behaviors. The following categories were examined during the study:

Use of Electronic Information Resources for Research. Among the eight types of electronic information resources, the Web was used by 29 (96.7\%) participants for research and information-gathering, databases were used by 27 (90.0\%) participants, e-journals were used by 26

\begin{tabular}{|c|c|c|c|c|}
\hline \multicolumn{5}{|c|}{$\begin{array}{c}\text { TABLE } 3 \\
\text { Numbers of Users and Average Years of Use for Various Electronic } \\
\text { Resources for Research }(n=30)\end{array}$} \\
\hline $\begin{array}{l}\text { Type of Internet } \\
\text { Resources }\end{array}$ & $\begin{array}{l}\text { Number of } \\
\text { Users }\end{array}$ & $\begin{array}{c}\text { Average Years } \\
\text { of Usage }\end{array}$ & $\begin{array}{l}\text { Standard } \\
\text { Deviation }\end{array}$ & $\begin{array}{c}\text { Range } \\
\text { (Min-Max) }\end{array}$ \\
\hline Web & $29(96.7 \%)$ & 6.8 & 2.8 & $2-12.5$ \\
\hline Databases & $27(90.0 \%)$ & 6.1 & 3.2 & $1.5-14$ \\
\hline E-journals & $26(86.7 \%)$ & 4.8 & 3.1 & $1-12$ \\
\hline E-mail & $25(83.3 \%)$ & 6.7 & 4.3 & $1.5-17$ \\
\hline Online Catalogs & $24(80.0 \%)$ & 7.4 & 5.0 & $1-17$ \\
\hline Listserv & $10(33.3 \%)$ & 5.4 & 5.1 & $1-16$ \\
\hline Portals & $10(33.3 \%)$ & 6.6 & 3.7 & $2-12$ \\
\hline FTP & $9(30.0 \%)$ & 6.7 & 4.0 & $3-12$ \\
\hline
\end{tabular}




\begin{tabular}{|l|c|c|c|c|c|}
\hline \multicolumn{7}{|c|}{ TABLE 4} \\
\multicolumn{1}{|c|}{ Frequency of Participant Use of Electronic Resources for Research } \\
\hline $\begin{array}{c}\text { Internet } \\
\text { Resources }\end{array}$ & $\begin{array}{c}\text { Multiple } \\
\text { Times a Day }\end{array}$ & Daily & Weekly & Monthly & Rarely \\
\hline Web & $4(13.8 \%)$ & $10(34.5 \%)$ & $13(44.8 \%)$ & $0(0 \%)$ & $2(6.9 \%)$ \\
\hline E-mail & $2(8.0 \%)$ & $8(32.0 \%)$ & $10(40.0 \%)$ & $2(8.0 \%)$ & $3(12.0 \%)$ \\
\hline Listservs & $0(0 \%)$ & $6(60.0 \%)$ & $1(10.0 \%)$ & $2(20.0 \%)$ & $1(10.0 \%)$ \\
\hline Databases & $0(0 \%)$ & $7(25.9 \%)$ & $15(55.6 \%)$ & $4(14.8 \%)$ & $1(3.7 \%)$ \\
\hline E-journals & $0(0 \%)$ & $4(15.4 \%)$ & $15(57.7 \%)$ & $5(19.2 \%)$ & $2(7.7 \%)$ \\
\hline Online Catalogs & $1(4.2 \%)$ & $2(8.3 \%)$ & $13(54.2 \%)$ & $6(25.5 \%)$ & $2(8.3 \%)$ \\
\hline Portals & $0(0 \%)$ & $2(20.0 \%)$ & $5(50.0 \%)$ & $2(20.0 \%)$ & $1(10.0 \%)$ \\
\hline FTP & $0(0 \%)$ & $0(0 \%)$ & $0(0 \%)$ & $3(33.3 \%)$ & $6(77.7 \%)$ \\
\hline
\end{tabular}

(86.7\%) participants, e-mail was used by $25(83.3 \%)$ participants, online catalogs were used by $24(80.0 \%)$ participants, listservs and portals were each only used by $10(33.3 \%)$ participants, and FTP was only used by $9(30.0 \%)$ participants (see table 3).

Frequency of Use and Number of Years of Use. More than 48 percent of the Web users interviewed visited the Web as an information-gathering tool daily or multiple times a day. Forty percent of e-mail users interviewed used e-mail as an informationgathering tool daily or multiple times a day. Sixty percent of listserv users were daily listserv readers. More than 80 percent of database users accessed them on a daily or weekly basis. More than 70 percent of e-journal users accessed e-journals daily to weekly. More than 80 percent of catalog users used online catalogs weekly or monthly. Seventy percent of portal users chose that avenue daily or weekly. More than 75 percent of FTP users rarely used it as the default research strategy. Data shows that the number of years of use does not necessarily relate to frequency of usage (see table 3 and table 4).

Importance Rankings of Various Electronic Information Resources. On a five-point scale ( 1 being the least important and 5 being the most important), the Web received the highest ranking, with a score of 4.5 on average, thus qualifying it as the most important popular electronic research resource used. Problems associated with Web use that was reported by participants include information overload, difficulty in conducting precise searches, the mixture of substantial and irrelevant sites, and difficulty in evaluating the credibility and actual sources of data.

Databases ranked second in importance. Many participants originally used databases in their traditional index forms, but later migrated to "transformed" databases, which they perceived as a powerful tool. The majority of researchers preferred subject databases containing an abundance of journal titles to find articles, as opposed to searching just one e-journal. Several users had only utilized the free databases that are available on the Web (such as the free basic version of the Education Resources Information Center site, or U.S. Census Bureau databases), and failed to benefit from the library's quality-controlled, feebased databases. Participants reported encountering difficulties stemming from problems with the functionality of the library's ILS or the university's network issues, inadequate search skills, terminological problems, and deficient knowledge of suitable databases for their academic field. Many were concerned about the availability of older, current, and full-text journal articles through databases.

Electronic journals were rated as the third most important resource. Some participants only used free e-journals on 
the Web because they were unfamiliar with paid subscription e-journals available at the library. Some participants were unclear as to the relationships between e-journals and databases and didn't see any differences between them. Some preferred e-journals because they could browse journals by tables of contents and read full-text articles. There were also concerns about the availability for some older, current, and full-text articles, as well as rare or lesser-known journals. Online catalogs were rated as the fourth most important electronic resource. Many participants browsed the library's online catalogs to locate the library's existing print and online resources, and some searched the online catalogs of other libraries, union/consortial catalogs (such as Athena, which includes academic and public libraries in the Nashville area), and publisher or vendors' online catalogs.

E-mail was rated as the fifth most important electronic resource, whereas listservs were the sixth most important. E-mail had become a common communication and networking tool for participants. It was a method for them to make contacts with experts, conduct interviews or surveys, and network with colleagues. Problems mentioned by participants are junk mail and unstable e-mail accounts.
Listservs were still fairly new to some participants. Some non-users reported that they are not familiar with the source or haven't been able to find any good listservs in their respective fields. Faculty and other academics take advantage of listservs to ask or answer questions, browse current information in their fields, locate information on conferences, discover new publications, and locate relevant calls for papers. Listservs, especially moderated ones, tend to be more focused and relevant to serious research.

Web portals were rated as the seventh most important electronic research resource. About two-thirds of the participants were not familiar with portals. The participants who did use portals liked them because they provided shortcuts that were ideal for people working on specific projects and those who wanted to keep up with special research interests. The most common problems with portals were the variance in quality and how quickly they became outdated, leading to issues such as dead links.

FTP was rated as the least important electronic research resource in this study. Users only occasionally need to transfer or download files using FTP, since today's browsers can easily handle most of their downloading tasks. FTP was predominantly viewed as outdated and obsolete (see table 5).

\begin{tabular}{|c|c|c|c|c|}
\hline \multicolumn{5}{|c|}{$\begin{array}{c}\text { TABLE 5 } \\
\text { Importance Rankings for Various Types of Electronic Information } \\
\text { Resources for Research }\end{array}$} \\
\hline Rank & Internet Sources & $\begin{array}{c}\text { Importance } \\
\text { Score }\end{array}$ & $\begin{array}{c}\text { Standard } \\
\text { Deviation }\end{array}$ & $\begin{array}{c}\text { Range } \\
\text { (Min-Max) }\end{array}$ \\
\hline 1 & Web & 4.5 & 0.9 & $1-5$ \\
\hline 2 & Databases & 4.4 & 0.8 & $2-5$ \\
\hline 3 & E-journals & 4.2 & 0.9 & $2-5$ \\
\hline 4 & Online Catalogs & 4.1 & 0.9 & $2-5$ \\
\hline 5 & E-mail & 3.6 & 1.4 & $1-5$ \\
\hline 6 & Listserv & 3.2 & 1.0 & $2-5$ \\
\hline 7 & Portal & 3.2 & 1.2 & $2-5$ \\
\hline 8 & FTP & 2.4 & 1.1 & $1-4$ \\
\hline
\end{tabular}




\begin{tabular}{|l|c|c|c|}
\hline \multicolumn{4}{|c|}{ TABLE 6 } \\
Percent of Participants' Research Needs Satisfied by Print vs. Electronic \\
Information Resources \\
\hline Type of Source & $\begin{array}{c}\text { Average Percentage } \\
\text { of Research Needs } \\
\text { Satisfied by Type }\end{array}$ & $\begin{array}{c}\text { Standard } \\
\text { Deviation }\end{array}$ & Range (Min-Max) \\
\hline Print Information & 42 & 19 & $10-90$ \\
\hline Electronic Information & 58 & 19 & $10-90$ \\
\hline
\end{tabular}

\section{Use of Electronic Resources vs. Use of Print Resources}

It was generally agreed that social scientists tend to rely heavily on periodicals, while humanities researchers rely more on books and primary sources. While both types of researchers use a wide range of information sources, their use of electronic sources is increasing. Overall, the participants used electronic resources to satisfy 58 percent of their research needs and print sources to satisfy 42 percent (see table 6). Indeed, many researchers displayed a marked preference for electronic resources over print.

\section{Special Cases}

Generally speaking, participants' opinions on electronic information resources were positive. However, even though on average 58 percent of the researchers' information needs are satisfied by electronic information resources, in certain cases, participants' information needs are mainly satisfied by print. These special cases are useful to bear in mind when discussing the varying opinions of participants.
It may provide perspective and insight to discuss the specifics of the cases cited in table 7. Case 1 is based on a full professor in the Teaching \& Learning Department. Accustomed to using print resources for most of his academic career, he was unfamiliar with new technologies and found electronic information resources difficult to understand and manage.

The participant in Case 2 is a senior researcher in the Communications Department. This professor primarily teaches Theater classes and avoided electronic information resources for the same reasons as the professor in Case 1. In addition, the participant had some concerns about the availability of electronic information resources for his research projects.

Case 3 involved a full professor in the History Department who was mainly concerned about the availability of the older materials in the discipline. For example, the participant commented:

Another thing is that six thousand years of human history is not avail-

\begin{tabular}{|c|c|c|c|}
\hline \multicolumn{4}{|c|}{$\begin{array}{c}\text { TABLE } 7 \\
\text { Percent of Participants' Research Needs Satisfied by Print vs. Electronic } \\
\text { Resources (Special Cases) }\end{array}$} \\
\hline Case & Disciplines & $\begin{array}{c}\text { Percentage Satisfied } \\
\text { by Print Resources }\end{array}$ & $\begin{array}{l}\text { Percentage Satisfied by } \\
\text { Electronic Resources }\end{array}$ \\
\hline Case 1 & Teaching \& Learning & 90 & 10 \\
\hline Case 2 & Communication & 80 & 20 \\
\hline Case 3 & History & 70 & 30 \\
\hline Case 4 & African Study & 70 & 30 \\
\hline Case 5 & Literature and Philosophy & 60 & 40 \\
\hline Case 6 & Education Administration & 60 & 40 \\
\hline
\end{tabular}


able online. ... If you think about local history, court records and deeds, none of them are available online. ... If you think about the priority of the government of the state of Tennessee, who is going to pay millions of dollars to have people digitize all of the court cases that go back to the 1700s? For historians, unless they do the research for very recent history, you have to really get to the print.

A faculty member in the Africana Studies Department served as the example for Case 4 . The professor was not familiar with the library's electronic information resources and found it hard to evaluate electronic resources on the Web. The nature of his research relied heavily upon field studies and he preferred the print data to the digitized.

Case 5 cites a professor in the Language \& Philosophy Department, who was a frequent user of electronic information resources, but who was concerned about the availability of electronic resources that supported his discipline at the university. The professor had previously requested a database for his field from the library and was planning to request a few more.
Case 6 is a doctoral student in the Education Administration Department who had concerns about the availability of older materials in electronic format.

\section{Use of Print vs. Electronic Resources by Rank and Gender}

Our data demonstrates diverse usage patterns for electronic information resources among users of different academic ranks. Doctoral students and assistant professors are more enthusiastic users of electronic information resources, relying on electronic resources more heavily for their research than associate and full professors. These junior researchers are presumably younger and more comfortable with emerging technologies. Indeed, doctoral students satisfied 61.7 percent of their research needs (12.2 SD) with electronic information resources, and assistant professors satisfied 70.0 percent of their research needs (15.1 SD) with electronic information resources. Conversely, senior researchers, perhaps less comfortable with new technology, chose to satisfy the majority of their research requirements with print resources, while associate professors satisfied 52.0 percent of their research needs (22.8 SD) and full profes-

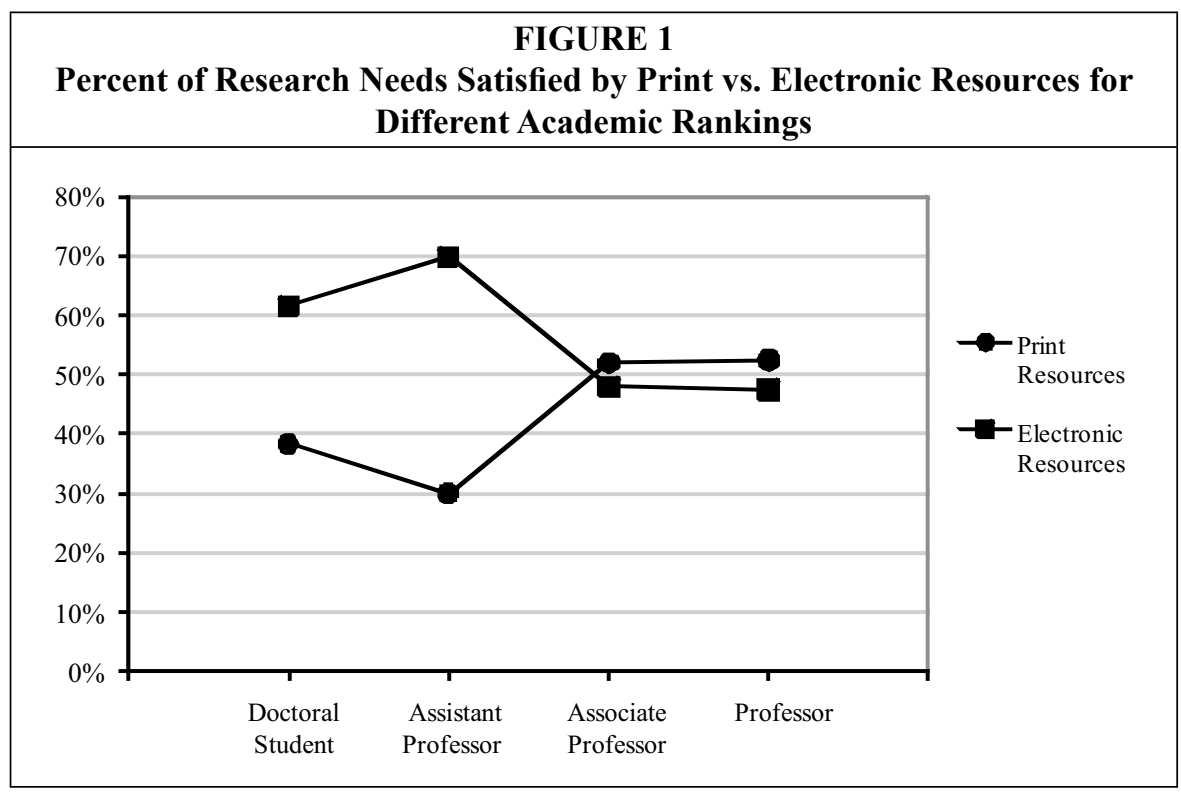


sors satisfied 52.5 percent of their research needs (21.9 SD) with print resources (see figure 1).

The author also examined how gender influences participants' use of electronic information resources. Our data revealed that male researchers approached electronic information resources slightly more than female researchers. Due to an uneven distribution of participants in terms of gender and rank, comparisons of means and standard deviations could only be made for two groups: doctoral students and assistant professors. Male doctoral students used electronic information resources for 63.8 percent of their research needs (SD 18.0), while female doctoral students used electronic information resources for 60.0 percent of their research needs (SD 8.2). Meanwhile, male assistant professors used electronic information resources for 80.0 percent of their research needs (SD 8.2), while female assistant professors used electronic information resources for 60.0 percent of their research needs (SD 14.1).

\section{Reasons for Use of Electronic Resources}

According to the responses, electronic information resources have a number of advantages over print.

1. Availability in Electronic Format-The amount of information available in electronic format has vastly increased over recent years. Participants appreciated the options provided by this increased availability.

It takes a lot of space to store my journals. I just don't subscribe to those very common journals now, such as American Journal of Sociology, because usually there is an online version, and I read the online journals. It saves money and space. (12S)

Well, the major historical journals are available online. American Historical Journal, Journal of Modern History and New York Review of Books are the e-journals that I read frequently. (14Hi)
2. Accessibility-Most electronic information resources are available anywhere, anytime to anyone with a computer, and participants appreciated this ease and convenience.

I started my research back in the '70s. I used to drive to a lot of libraries, and to search their card catalog to see what they have. It is so convenient and effective to use e-sources. So much information is online. I can at least find what a library has through their online catalogs. If I really need something, I can get it through interlibrary loan. (12S)

3. Usability - The majority of scholars responding to the questionnaire cited the usability features of electronic information resources. They enjoyed the convenience of saving and printing, the frequency of updating and the powerful potential of search functions. They especially appreciated the ease of sharing information and sending papers to other researchers.

Electronic resources are convenient, easy to use and easy to access. (8E)

It is easy to do the searches. With the computer, I can do Boolean searches and use multiple terms. The computer does all the searches for me that I used to do the long way. (5Ho)

4. Source Quality - Professors and doctoral students also cited the specificity, quality, and reliability of certain electronic resources, such as government sites and e-journals.

I use databases to search for peerreviewed journal articles. (4E, $8 \mathrm{E}$, $11 B, \ldots)$ I use e-journals to search for peer-reviewed journal papers. $(12 \mathrm{~S}, \ldots .$.

If you see something like New York Times, National Journal on the Web, you technically assume these have gone through the same referee pro- 
cess, or if you see American Political Science Review on the Web, you assume what is there has gone through the same peer-reviewed process. You see these publications on the Web; you assume they go through the same peer-reviewed process, same referee process in that publication. (16P)

5. Disciplinary and Research Topic Specificity-All of the respondents in this study used electronic information resources for their research to some extent, but some used electronic information resources more, depending on the nature of available information for their disciplines. Many participants would have used more electronic resources if more had been made available in their discipline or area of interest.

I use their catalogs to find what they have in sociology and the historical information. For example, for my project about history of sociology, I use the university's online catalogs to find who wrote the dissertations about sociology at the beginning of the program for those universities. (12S)

If I am working on a very current cutting edge topic like teaching e-poetry or digital poetry, it works multi-dimensionally and includes a wide scope of activities. E-poetry cannot exist in a traditional journal. The e-poetry is mixed with words, images, job descriptions, and many other interactions. These are things that cannot exist in a traditional journal. (18W)

6. Belief in Efficacy-Many researchers clearly possessed positive attitudes toward electronic information resources, believing these resources to be timesaving, convenient, and effective.

I mostly use electronic resources now and am learning to use more. I download things I read online. I try to copy and paste things I find online. Hardcopy is nicer. But I am adjusting myself and learning to read more online, because we can get so much through e-resources, and we can't get away from it. (13S)

I love electronic resources. ... Anything to avoid stacking papers, I am delighted. It gives you more opportunities to find information. (23Ho)

\section{Obstacles to the Use of Electronic Resources}

Data was analyzed to gain insight into reasons for non-use or low use of electronic information resources for research purposes. Several factors were mentioned by participants:

1. Lack of Availability-Participants felt that some information was not available in electronic format. For example, the amount of electronic information resources available to humanities researchers is low, compared to that available to social sciences researchers. Information collected from this study supports the notion that the creation of digital archives for infrequently held materials would be an enormous benefit to certain faculty.

Most of the books don't have an electronic version. Therefore, we rely on print. (13S)

2. Lack of Accessibility-Electronic resource availability varies by institution. The library's services, the individual's awareness of the resources, and the person's research skills also influence accessibility of information. The data made evident that many of the participants encountered significant obstructions to information access, such as unavailability of desired sources or unstable or hard-touse ILS systems.

There are times that the library systems are down, and there is no way to use the library's E-resources when I need to. That is one problem with E-resources. (3E) 
Many times I can't find full-text for many articles through the Eresources, and can't access most recent and archived issues. $(22 \mathrm{Ho})$

3. Usability Issues - Content organization, interface, and choice of computer system all affect the usage of electronic information resources. The findings of the study proved that a well-designed library homepage, good information literacy skills, and user education are all important. For example, two professors $(13 \mathrm{~S}, 14 \mathrm{Hi})$ complained that the TSU library didn't have ProQuest. In fact, the library subscribed to a number of ProQuest databases but listed them separately on its database Web page. The author mentioned this to the public services librarians and the Web master reformatted the Web page to list the databases under the providers, such as ProQuest, Sage, etc. Incomplete cataloging of digital material can also be an issue, since electronic information sources change so quickly. It is important to provide more consistent digital cataloging, especially Persistent Uniform Resource Locators (PURLs).

It is time-consuming for me to search the electronic resources, and sometimes navigating between links is also confusing. (21T)

4. Uneven Source Quality-The results of the study strongly indicated that many participants suffered from information overload and were in need of specific and accurate information for their research. Not all participants are confident that electronic information resources provided accurate, reliable, and high-quality information.

There is so much false information and garbage on the Web. Information on the Web increases rapidly, and a lot of it is just garbage in and garbage out. (24A)

5. Disciplinary and Research Topic Constraints-Researchers' disciplines or research topics may influence their usage of electronic resources. As can be seen in table 8 , the two broad disciplinary categories in this study show different usage patterns.

Some disciplines and research projects require less extensive information-gathering from published resources, relying instead on field studies and interviews.

Historians use probably less digital information than most of the social scientists, because they are using primary sources and archives so much. (14Hi)

When you do field studies, they are kind of connected to the technology in the field. But technology doesn't do everything, and some of these have to be done by people. Human intelligence is needed. ... Technology is good in many ways, but it still can't do everything for field studies. I like primary material and collect row data for my field studies. (24A)

\begin{tabular}{|c|c|c|}
\hline \multicolumn{3}{|c|}{$\begin{array}{c}\text { TABLE } 8 \\
\text { Percent of Research Needs Satisfied by Print vs. Electronic Resources for } \\
\text { Social Sciences and Humanities Researchers }\end{array}$} \\
\hline Broad Disciplinary Category & $\begin{array}{c}\text { Percent of Needs Satisfied } \\
\text { by Print Resources }\end{array}$ & $\begin{array}{c}\text { Percent of Needs Satisfied } \\
\text { by Electronic Resources }\end{array}$ \\
\hline \multirow[t]{2}{*}{ Social Sciences } & 36.7 (Mean) & $63.3($ Mean $)$ \\
\hline & $18.0(\mathrm{SD})$ & $18.0(\mathrm{SD})$ \\
\hline \multirow[t]{2}{*}{ Humanities } & 60.0 (Mean) & 40.0 (Mean) \\
\hline & $14.0(\mathrm{SD})$ & $14.0(\mathrm{SD})$ \\
\hline
\end{tabular}


6. Perceived Ease of Use-Participants liked print materials because they were convenient, portable, and comfortable to use. Many participants mentioned the discomfort of reading on a computer screen, preferring to print out materials instead. Print materials can also be easier to access, browse, and manage.

I can read print materials without a computer and Internet, and take them with me and read them anywhere comfortably. (21T)

7. Lack of Awareness - The data established that participants may not be fully aware of all the relevant electronic resources available to them through the library. Specific recommendations (for instance, for a particular database or Web site) can influence a researcher's use of sources.

I am not familiar with this resource, but it sounds interesting. (4E)

\section{Personal Constraints-Personal} constraints are situational. Some users believed that they were too busy or "too old" to learn to effectively use electronic information resources, or that learning to use them was too difficult.

TSU library has many databases. I am only using a few of them, and I am not familiar to the rest of them. I don't have time to go through all of them and try to figure out what they are all about. (11B)

\section{Interview Results and the Ellis Model}

The six characteristics of the Ellis model seem to be fairly applicable to participants' use of electronic information resources. For example, "browsing" Web pages or e-journals does not seem radically different in nature from browsing tables of contents in journal articles or book chapters. Many responses clearly confirm the relevance of Ellis's informationseeking model, especially the chaining, monitoring, browsing, differentiating, and extracting stages. Examples follow:

\section{Starting}

Sometimes you say that here is something I am interested in, here is something I really want to go look at, so you start your research with that purpose. But I think other times, you are going to be out there looking at things, reading things, hearing things, and seeing things, and some thoughts might just pop up at you. Some thoughts might just hit you in the way that you say, that is interesting and I have never thought about that; and I think I want to go look at that and explore that. (16Hi)

\section{Chaining}

For me, the most important aspect of the model is "chaining." The reference lists from e-journals are excellent starting points. (8E)

I found a bibliography about religion and spirituality on the Web yesterday. I bookmarked the site, and also saved it on the disk. I can try to find some materials from that bibliography later. (10A)

\section{Browsing}

I do a lot of browsing. Now I browse on the Internet a lot, but before I might have gone to a library to look at the latest copies of various journals. I look at the tables of contents, abstracts and references. Now I can do that online. (21Ho)

\section{Monitoring}

I monitor a chat room for the former members of Franciscan priests, and I get a lot of quotes from that chat room. Then I don't have to interview those people. I also monitor four print journals regularly. (12S)

I think because of the Web and other electronic resources, monitoring 
almost precedes starting. Sometimes one doesn't have an idea until he/she picks it up in the medium.... I think we rely more on monitoring and browsing now. I think monitoring has become a constant step. With the changing media, it is no longer a linear process. I monitor even before I start a specific research topic, because that is where I am going to gain a lot for the topic in some ways. I think browsing and monitoring have become things that are no longer part of the process, but that supersede the process. I have them going on all the time. (18W)

\section{Differentiating}

Now differentiating and extracting have become a lot more complicated. Evaluating, depending on where you get the materials from, can be difficult. One has to figure out where the material comes from, who produced it, and how current it is. The whole idea about how current information is has changed radically. (18W)

I definitely do differentiating. I will look for the article by the same author, particularly in the educational field. Some authors are well-known in the field. When I was working on my dissertation, I would read five, six or seven articles from the same author to see if that author changed his/her perception over time. (23Ho)

\section{Extracting}

I take differentiating and extracting as two different levels of sorting. You initially sort, and then sort finer when you get close to what you need. $(17 \mathrm{Hi})$

Once I confirm the topic of my research, I go to the Web site (mainly TSU online databases) to search for sources related to my research. I read the abstracts and then scan the contents of the materials in order to decide whether or not to use the materials. If I need the materials and they are full-text linked, I will print them out right away. If not, I go to the library and copy the materials, or request the materials through the interlibrary loan. (9T)

All of the interviewees agreed that Ellis's model describes the basic process of searching for information. They have used part or all of the stages in the model at one time or another and many of the respondents' answers fit the model extraordinarily well. Analysis of the data, however, indicates that some revisions to the basic model are needed, because several informationseeking activities or tasks could not be categorized into the six characteristics. Two new characteristics emerged inductively during the course of data analysis.

"Preparation and planning" could be a new characteristic. Effective searching requires planning, attention to detail, and successful search strategies. Faced with an overload of information, it is important to find out which sources are useful, and to discover effective and simple search procedures. To undertake an effective search, one must use a range of tools and technology that enable information to be identified, located, and obtained. For example, to conduct an effective search, one needs to figure out what one is really researching, come up with keywords and synonyms, and use phrases, truncation, Boolean searches, and field searching, as appropriate. Data revealed that "preparation and planning" could be an additional stage in the model:

Before starting, I explore and diagnose the research problems, create a visual or mental picture to see how I should proceed with my research, and develop valid solutions. (1E)

I enjoy using electronic resources, but sometimes they can be overwhelming. For example, if I don't 
pick the proper search terms, sometimes I get thousands of results, and it is hard to sort out the relevant results. Sometimes I don't get any results, or not enough. This is one problem for e-sources. Electronic resources can save time, but sometimes they can be time-consuming also. (6T)

As researchers uncover more resources in an increasingly data-rich world, information management becomes more and more important and challenging. Many participants find it difficult to organize the digital materials they collect. Researchers can cope with large quantities of information through a variety of strategies, but effective tools are needed for information management. "Information management" thus could potentially qualify as a new characteristic, as indicated by these participant responses:

"Revising" is one stage that I use for my information gathering. I go back and update or discard information as the knowledge base expands. For instance, I gathered some information about six months ago for an ongoing research project. As information expands so fast today, I found more relevant materials for the project. Some of the information I found about six months ago is not important to me anymore, so I went back to reorganize the material I have, and discarded some of it. (8E)

Even for the materials I find through e-resources, I like to print them out and read the hard copies. It is much easier to flip the pages back and forth for the hard copies, and I can also make notes or clip parts of them and paste them to different places. It is much easier for me to organize hard copy materials. (10A)

It is much easier for me to read, store and organize print material, and it is more reliable for me too. I always prefer a hard copy. Once I have it, I always have it. (21T)

If I can get articles electronically, I will save the articles on my hard drive if it is something that I want to keep. If it is something really important, I might print it out. But more often I would save it. (23Ho)

Thus, our data showed that "preparation and planning" and "information management" are major information-seeking activities that could be potentially be added to David Ellis's behavioral model.

\section{Conclusions}

This study explored the degree to which specific electronic resources are significant to the social sciences and humanities researchers. The study found that electronic information resources played an essential role in these researchers' informationseeking pursuits. Among the eight types of Internet information technologies rated, the Web, databases, and e-journals are ranked first, second, and third in importance, followed by online catalogs and e-mail. Social sciences researchers use electronic information resources more often than humanities researchers. Doctoral students and assistant professors (both academically junior) have a higher rate of usage of electronic information resources than their more senior colleagues. All of the participants surveyed utilized electronic resources for their research at some point in the research process, and will continue to employ them as a means of gathering information. Easy access to information anytime and anywhere is important to these researchers, making them desire even more electronic information resource availability. In certain disciplines, however, electronic resources are perceived to be less available and/or less necessary to the researcher's field of expertise. The study also explored the degree to which Ellis's model remains relevant in the age of electronic resources and confirmed 
that the characteristics proposed by Ellis's model continue to play viable roles in research activities. These characteristics take place in both traditional research environments which rely on print and the electronic information environment. Many participants mentioned that these characteristics do not necessarily occur in the sequence outlined in the study's interview, or can take place concurrently with the other characteristics. As researchers progress from one activity to another, and their use of the characteristics will depend on their individual needs and situations. In addition to the six original characteristics (starting, chaining, browsing, monitoring, differentiation, and extracting), this study suggests two new characteristics: preparation and planning and information management. These new stages of research development reflect social sciences and humanities researchers' methods for locating relevant information. The two new characteristics identified in this study suggest a need for additional research tools and for more flexible and user-friendly information systems. The findings of this investigation indicate that obstacles to the increased use of electronic resources include perceptions of availability and usability. With research data becoming more accessible than ever before, there are many new opportunities for libraries to expand and innovate their functions in today's electronic information environment. The areas for innovation and entrepreneurship in the information science field include interfacing, information retrieval, user instruction, standardization, classification, information management, preservation, and organization of networked information sources that focus more on users. Academic libraries must integrate technology and traditional services, making libraries the gateways to the vast wealth of print and electronic information now available, which will encourage library usage and enhance patron satisfaction.

Indeed, such changes are taking place at libraries nationwide. At the Tennessee State University, where this research was conducted, the library now has added two smart classrooms offering library orientations and bibliographic instruction; professors can request these online. In addition, the Embedded Librarian Program was successfully implemented in 2007. This program provides collaboration with faculty in teaching information literacy skills, either online or "on the ground."

In 2004, when the study was conducted, the library had DRA, which lacked sufficient functionality, but the library migrated to Innovative Millennium system in 2005, and was able to provide better services. The migration to Innovative Millennium system allowed more functionality and user friendly features that include the addition of ebook records, serials MARC records, and book reviews to make the online catalog more user friendly. The redesign of the Web OPAC page, the addition of a link resolver, the availability of federated searching, and the addition of more databases, ebooks, and e-journal packages, have combined to increase the library traffic from oncampus and remote users. The library has submitted a proposal for a new Learning Commons. The library offers orientation classes to new faculty at the beginning of each semester and invites academic departments to visit the library for information literacy sessions tailored to their field.

Major transformations have occurred in the digital world since this research was conducted in 2004. Web 2.0 technologies such as Facebook, Flickr, blogs, YouTube, and Twitter have emerged. Social networking software offers a new approach for academic libraries, since it allows library users to build relationships with library staff and other library users. Libraries are now looking to stay connected to users through various forms of social media. The Brown-Daniel Library at Tennessee State University started using Twitter and Facebook in 2009, and the library dean has started a blog.

The rise of Facebook, Twitter, blogs, and other social computing tools has undoubtedly influenced the information- 
seeking behaviors of scholars. New tools such as RSS aggregators, Google Books, mobile computing, Zotero, and the open access archives and repositories are also likely to change the ways that researchers access and use technology. These new and emerging technologies may be having a significant research impact that this article does not address, therefore meriting further exploration and study.
Given the changes that have taken place in the field of electronic information resources since this research was completed, it would be of interest to conduct additional studies to investigate how researchers' use of library and Internet resources continue to adapt and evolve as they continue to conduct research in the fluid world of digital information resources.

\section{Notes}

1. Ellis, David. "A Behavioral Approach to Information Retrieval Design." Journal of Documentation 45, no. 3 (1989): 171-221

2. Sely Costa and Jack Meadows, "The Impact of Computer Usage on Scholarly Communication among Social Scientists," Journal of Information Science 26, no. 4 (2000): 255-62.

3. Hannah Francis, "The Information-Seeking Behavior of Social Faculty at the University of the West Indies, St. Augustine Campus," Journal of Academic Librarianship 31, no. 1 (Jan. 2005): $67-72$.

4. David Ellis and Hanna Oldman, "The English Literature Researcher in the Age of the Internet," Journal of Information Science 31, no. 1 (2005): 29-36.

5. Stephen E. Wiberley, Jr. and William G. Jones, "Time and Technology: A Decade-Long Look at Humanists' Use of Electronic Information Technology," College \& Research Libraries 61, no. 5 (2000): 421-31.

6. Margaret Stieg Dalton and Laurie Charnigo, "Historians and Their Information Sources," College \& Research Libraries 65, no. 5 (2004): 400-25.

7. Susana Romanos de Tiratel, "Accessing Information Use by Humanists and Social Scientists: A Study at the Universidad de Buenos Aires, Argentina," Journal of Academic Librarianship 26, no. 5 (2000): $346-54$.

8. Peiling Wang, "Information Behaviors of Academic Researchers in the Internet Era: An Interdisciplinary \& Cross-cultural Study," 1st International Scientific Conference eRA: the Information Technology to Science, Economy, Society \& Education, September 16-17, 2006.

9. Peiling Wang, D.A. Dervos, Yan Zhang, and Lei Wu, "Information-seeking Behaviors of Academic Researchers in the Internet Age: A User Study in the United States, China and Greece," in Proceedings of the 69th Annual Meeting of the American Society for Information Science \& Technology, Milwaukee, WI, October 19-24, 2007.

10. Carole L. Palmer, Lauren C. Teffeau, and Carrie M. Pirmann, "Scholarly Information Practices in the Online Environment," Dublin, OH: OCLC, 2009.

11. Clara M. Chu, "Literary Critics at Work and Their Information Needs: A Research-phases Model," Library E Information Science Research 21, no. 2 (1999): 247-73.

12. David. Ellis, "A Behavioral Approach to Information Retrieval Design," Journal of Documentation 45, no. 3 (1989): 171-212.

13. David Ellis, "Modeling the Information-Seeking Patterns of Academic Researchers: A Grounded Theory Approach," The Library Quarterly 63, no. 4 (1993): 469-86.

14. Chun W. Choo, Brian Detlor, and Don Turnbull, "A Behavioral Model of Information Seeking on the Web: Preliminary Results of a Study of How Managers and IT Specialists Use the Web," in Proceedings of the ASIS Annual Meeting 35 (1998): 290-302.

15. Chun W. Choo, Brian Detlor, and Don Turnbull, "Information Seeking on the Web: An Integrated Model of Browsing and Searching," 2000. Available online at http://firstmonday.org/ htbin/cgiwrap/bin/ojs/index.php/fm/article/view/729/638. [Accessed 10 May 2010].

16. Donald O.Case, Looking for Information. San Diego, CA: Academic Press, 2002.

17. Lokman I.Meho and Stephanie W. Haas, "Information-Seeking Behavior and Use of Social Science Faculty Studying Stateless Nations: A Case Study," Library and Information Science Research 23, no. 1 (2001): 5-25.

18. Lokman I. Meho and Helen R.Tibbo, "Modeling the Information-Seeking Behavior of Social Scientists: Ellis's Study Revisited," Journal of the American Society for Information Science and Technology 54, no. 6 (2003): 570-87. 


\section{Appendix A: Interview Guideline}

\section{Task Analysis}

This is the core part of the interview. The participants will be asked to respond to a series of questions, such as their information use patterns, methods of locating information, problems encountered in the research process, methods of keeping abreast of new developments in the field, help-seeking behavior, and use of information technology, with a particular emphasis on electronic resources.

Initial interview questions.

Rank of the Participant: Department: No.

[Greet, explain the project briefly, consent form, \& set recording] 1. Could you briefly describe one of your recently completed research projects, in which you have used various information resources?

2a. Do you use e-mail to gather information for your research?

$\square$ Yes. $\square$ No. Reason for not using the source [If no, go to question 3]

2b. How often do you use e-mail to gather information for your research?

2c. How long have you been using e-mail to gather information for your research?

$2 \mathrm{~d}$. How would you rate the importance of e-mail as a tool for gathering information for your research? Let's use a scale of 1 to 5,1 for the least important and 5 for the most important.

1

23

4

5

3a. Do you use listservs to gather information for your research?

$\square$ Yes. $\square$ No. Reason for not using the source

[If no, go to question 4]

3b. How often do you use listservs to gather information for your research?

3c. How long have you been using listservs to gather information for your research?

$3 \mathrm{~d}$. How would you rate the importance of listservs as a tool for gathering information for your research? Let's use a scale of 1 to 5,1 for the least important and 5 for the most $\begin{array}{llllll}\text { important. } & 1 & 2 & 3 & 4 & 5\end{array}$

3e. Would you please give me a few examples for your most frequently used listservs for the research?

4a. Do you use the Web to gather information for your research?

$\square$ Yes. $\square$ No. Reason for not using the source

[If no, go to question 5]

4b. How often do you use the Web to gather information for your research?

4c. How long have you been using the Web to gather information for your research? 
$4 \mathrm{~d}$. How would you rate the importance of the Web as a tool for gathering information for your research? Let's use a scale of 1 to 5, 1 for the least important and 5 for the most $\begin{array}{llllll}\text { important. } & 1 & 2 & 3 & 4 & 5\end{array}$

5a. Do you use FTP to gather information for your research?

$\square$ Yes. $\square$ No. Reason for not using the source

[If no, go to question 6]

$5 b$. How often do you use FTP to gather information for your research?

5c. How long have you been using FTP to gather information for your research?

$5 \mathrm{~d}$. How would you rate the importance of FTP as a tool for gathering information for your research? Let's use a scale of 1 to 5,1 for the least important and 5 for the most $\begin{array}{llllll}\text { important. } & 1 & 2 & 3 & 4 & 5\end{array}$

6a. Do you use online catalogs to gather information for your research?

$\square$ Yes. $\square$ No. Reason for not using the source

[If no, go to question 7]

6b. How often do you use online catalogs to gather information for your research?

6c. How long have you been using online catalogs to gather information for your research?

$6 \mathrm{~d}$. How would you rate the importance of online catalogs as a tool for gathering information for your research? Let's use a scale of 1 to 5, 1 for the least important and $\begin{array}{llllll}5 \text { for the most important. } & 1 & 2 & 3 & 4 & 5\end{array}$

7a. Do you use e-journals to gather information for your research?

$\square$ Yes. $\square$ No. Reason for not using the source [If no, go to question 8]

7b. How often do you use e-journals to gather information for your research?

7c. How long have you been using e-journals to gather information for your research?

$7 \mathrm{~d}$. How would you rate the importance of e-journals as a tool for gathering information for your research? Let's use a scale of 1 to 5,1 for the least important and 5 for the $\begin{array}{llllll}\text { most important. } & 1 & 2 & 3 & 4 & 5\end{array}$

7e. Would you please give me a few examples for your most frequently used electronic journals for the research?

8a. Do you use databases to gather information for your research?

$\square$ Yes. $\square$ No. Reason for not using the source

[If no, go to question 9]

$8 \mathrm{~b}$. How often do you use databases to gather information for your research?

8c. How long have you been using databases to gather information for your research? 
$8 \mathrm{~d}$. How would you rate the importance of databases as a tool for gathering information for your research? Let's use a scale of 1 to 5,1 for the least important and 5 for the most important. 1

8e. Would you please give me a few examples of your most frequently used databases for the research?

9a. Do you use portals to gather information for your research?

$\square$ Yes. $\square$ No. Reason for not using the source

[If no, go to question 10]

9b. How often do you use portals to gather information for your research?

9c. How long have you been using portals to gather information for your research?

9d. How would you rate the importance of portals as a tool for gathering information for your research? Let's use a scale of 1 to 5,1 for the least important and 5 for the most $\begin{array}{llllll}\text { important. } & 1 & 2 & 3 & 4 & 5\end{array}$

9 e. Would you please give me a few examples for your most frequently used portals for the research?

[For nonusers of e-resources, go to question 12 and 13.]

10. How are the above information resources used in your research process?

\{This is the most important question of all. Make sure they elaborate on how the esources were used, and why.\}

e-mail:

listserv:

Web:

FTP:

online catalogs:

databases:

electronic journals:

portal:

11. In comparison between print information resources and electronic information resources, which percentage of your research information needs is satisfied by each type?

Print information

Electronic information

12. There is a model that depicts six types of information seeking. I am interested in your experiences in finding information for your research. Could you look at the model [give the interviewee a copy of the model] and provide your comments?

13. Is there anything you would like to add to what we have discussed?

\{Thank you very much!\} 